\title{
Physico-chemical properties of Brazilian cocoa butter and industrial blends. Part I - Chemical composition, solid fat content and consistency
}

\author{
By A.P.B. Ribeiro ${ }^{a, *}$, R. Claro da Silva ${ }^{b}$, L.A. Gioiellib, M.I.de Almeida Gonçalves ${ }^{b}$, R. Grimaldi ${ }^{\mathrm{c}}$, \\ L.A.G. Gonçalves ${ }^{c}$ and T. Guenter Kieckbusch ${ }^{a}$
}

\author{
${ }^{a}$ School of Chemical Engineering, University of Campinas, Campinas, Brazil. \\ ${ }^{\mathrm{b}}$ Faculty of Pharmaceutical Sciences, University of São Paulo, São Paulo, Brazil. \\ ${ }^{c}$ Faculty of Food Engineering, University of Campinas, Campinas, Brazil. \\ *Corresponding author: badanribeiro@yahoo.com.br
}

\section{RESUMEN}

Propiedades físico-químicas de la manteca de cacao de Brasil y mezclas industriales. Parte I - Composición química, contenido de grasa sólida y consistencia.

En este trabajo se presenta un estudio comparativo de las propiedades primarias de mantecas de cacao, representativas de las mezclas industriales, y de la manteca de cacao original de diferentes zonas geográficas de Brasil. Las muestras fueron evaluadas de acuerdo a la composición de ácidos grasos, composición de triglicéridos, distribución de los ácidos grasos en las moléculas de triglicéridos, punto de fusión, contenido de grasa sólida y consistencia. Los resultados permitieron diferenciar las muestras por su composición química, propiedades de resistencia térmica, características de dureza, así como en materia de adecuaciones tecnológicas y los usos potenciales en las regiones de clima tropical.

PALABRAS CLAVE: Composición química - Contenido de grasa sólida - Dureza - Manteca de cacao - Punto de fusión - Resistencia térmica.

\section{SUMMARY}

Physico-chemical properties of Brazilian cocoa butter and industrial blends. Part I Chemical composition, solid fat content and consistency .

A comparative study of the primary properties of six cocoa butter samples, representative of industrial blends and cocoa butter extracted from fruits cultivated in different geographical areas in Brazil is presented. The samples were evaluated according to fatty acid composition, triacylglycerol composition, regiospecific distribution, melting point, solid fat content and consistency. The results allowed for differentiating the samples according to their chemical compositions, thermal resistance properties, hardness characteristics, as well as technological adequacies and potential use in regions with tropical climates.

KEYW-ORDS: Cocoa butter - Chemical composition - Hardness - Melting point - Solid fat content - Thermal resistance.

\section{INTRODUCTION}

Cocoa butter is the most important component used in chocolate and confectionery manufacturing.
It is obtained from the cocoa fruit (Theobroma cacao), commonly cultivated in equatorial areas, mainly in western Africa, South America, Central America and eastern Asia (Shukla, 2006). Cocoa butter represents the continuous phase of this product, serving as a dispersant matrix for solid cocoa particles, sugar and milk. In addition, it is responsible for several quality attributes of the final product, such as hardness and brittleness at room temperature (snap), brightness, contraction during demolding and complete melting at mouth temperature with rapid flavor release at taste. It is the most expensive ingredient in chocolate manufacturing, corresponding to 25 to $36 \%$ of the cost of the finished product (Timms, 2003).

Cocoa butter presents a unique chemical composition, responsible for its unique sensorial attributes. The types of fatty acids and their positional distribution of triacylglycerol (TAG) molecules determine the physical properties of cocoa butter and its general characteristics for industrial use. The main fatty acids found in cocoa butter are palmitic, stearic and oleic acids, whose levels correspond to approximately 25,36 and $35 \%$ of total the fatty acid content, respectively. The TAGs in cocoa butter are predominantly composed of 1,3-dipalmitoyl-2-oleoyl-glycerol (POP), 1-palmitoyl2-oleoyl-3-estearoyl-glycerol (POSt) and 1,3-diestearoil-2-oleoyl-glycerol (StOSt) and the oleic acid occupies, preferibly, the sn-2 position of the structure. This relatively uniform triacylglycerol composition confers a thermal and structural behavior to cocoa butter which is comparable to a pure compound (Subramaniam, 2000).

Interrelationships among the chemical compositions and physical properties of cocoa butter exert a great influence on the quality and acceptance of chocolate and confectionery products. Sensorial attributes, shelf life and stability during storage are directly dependent on the chemical composition and properties of the fat phase. Therefore, the solid profile, consistency, microstructure, polymorphism and melting and crystallization behaviors of cocoa butter are reflected as primary factors related to its 
functionality for industrial applications (Norberg, 2006; Awad and Marangoni, 2006).

Variations in cocoa butter composition can result in unacceptable physical properties, such as excessive softness and high susceptibility of the final product to fat bloom. In addition to these drawbacks, difficulties during processing (especially at tempering) or incompatibility of the fat phase with the climate conditions of the producing and consuming areas are also consequences of slight changes in the TAG profile (Chaiseri and Dimick, 1995; El-Mallah and Megahed, 1998).

Studies indicate that the fatty acid profile and TAG composition of cocoa butter and its ascribed properties, such as melting point, solid profile and consistency, depend on geographical areas of cultivation and their different climate conditions, especially the temperature (Gunstone and Harwood, 2007; Tucci et al., 1996). Data on chemical composition reveal that cocoa butter produced in South America contains levels of oleic acid significantly higher than those from Africa and Asia. Studies reveal that Brazilian cocoa butter presents lower monounsaturated TAG and higher diunsaturated TAG contents, when compared to species produced in other countries. As a result, its crystallization behavior is, more often, unsatisfactory (Lipp and Anklam, 1998). In Brazil, however, regional climate differences and transport/storage conditions require the use of cocoa butter of superior hardness and with high thermal resistance. A commercial, although partial solution in practice for this problem is the use of cocoa butter blends obtained from mixtures of the almonds from several countries, in order to get a more consistent product (Timms, 2003). The fundamental physico-chemical characteristics of these industrial blends and their performance in relation to the cocoa butter produced in Brazil are not disclosed in the scientific literature, although the expressive national volume of production of this raw material represents a strategic product from an economic point of view.

The objective of this work was to perform a comparative study of the chemical and physical attributes of six different cocoa butter samples. Three different industrial standard blends and cocoa butter samples obtained from trees cultivated in three different Brazilian regions were investigated. The samples were characterized according to their fatty acid composition, triacylglycerol composition, regiospecific distribution, melting point, solid fat content and consistency.

\section{MATERIALS AND METHODS}

\subsection{Material}

Raw-materials. Samples from three different Brazilian industrial blends were evaluated. The samples were obtained directly from the processing plants of cocoa almonds and represent industrial standard cocoa butter commercially available in
Brazil, composed of mixtures of cocoa butter from different geographic origins to ensure the constant physical properties required for use in tropical areas. The industrial standard samples named Blend $\mathrm{A}$, Blend $\mathrm{B}$ and Blend $\mathrm{C}$ were provided by three different industries, which, together, are responsible for the processing of more than $70 \%$ of the cocoa beans in Brazil (Codevasf, 2009). The geographical origin of the almonds and the blending proportions, however, were not reported by the suppliers. Three national cocoa butter samples originating from different Brazilian states (Bahia, Amazonas and Espírito Santo) were selected and labelled Braz A, Braz B and Braz C, respectively. These samples were obtained from regional producers, between January-April 2010, through a Brazilian agency responsible for regional cocoa production politics. The samples represent the harvest in the three main microclimates for cocoa farming in Brazil (Codevasf, 2009). All cocoa butter samples were produced by cold pressing and deodorized. They were stored in polyethylene jars in a cold chamber $\left(10^{\circ} \mathrm{C}\right)$, until use.

\subsection{Analytical Methods}

Fatty acid composition. The Analyses of fatty acid composition were performed in duplicate in a capillary gas chromatograph (CGC Agilent 6850 Series GC System, Santa Clara, California, USA), after esterification using Hartman and Lago's method (Hartman and Lago, 1973). The fatty acid methyl esters were separated according to AOCS Ce 2-66 method (AOCS, 2004) in a DB23 Agilent capillary column ( $50 \%$ cyanopropyl-methylpolysiloxane), with the following dimensions: length: $60 \mathrm{~m}$, internal diameter: $0.5 \mathrm{~mm}$ and $0.25 \mathrm{~mm}$ film thickness. Analysis conditions: oven temperature program: $110^{\circ} \mathrm{C}$ for 5 minutes, $110{ }^{\circ} \mathrm{C}-215^{\circ} \mathrm{C}\left(5^{\circ} \mathrm{C} / \mathrm{min}\right)$, $215^{\circ} \mathrm{C}$ for 24 minutes; detector temperature: $280^{\circ} \mathrm{C}$; injector temperature: $250{ }^{\circ} \mathrm{C}$; carrier gas: helium; split ratio 1:50; injected volume: $1.0 \mu \mathrm{L}$. The qualitative composition was determined by comparing peak retention times with the respective standards for fatty acids. The quantitative composition was performed by area normalization, expressed as mass percentage. The average of two injections is reported.

Triacylglycerol composition. An analysis of the composition of TAGs was performed in a CGC Agilent 6850 Series GC System (Santa Clara, California, USA) capillary gas chromatograph. A DB17HT Agilent Catalogue: 122-1811 capillary column (50\%-phenyl-methylpolysiloxane, with $15 \mathrm{~m}$ length $\times 0.25 \mathrm{~mm}$ internal diameter, coated with film of $0.15 \mu \mathrm{m}$ ) was used. Conditions: split injection, ratio of 1:100; column temperature: $250{ }^{\circ} \mathrm{C}$, programmed to $350{ }^{\circ} \mathrm{C}$ at the rate of $5{ }^{\circ} \mathrm{C} / \mathrm{min}$; carrier gas: helium at a flow rate of $1.0 \mathrm{~mL} / \mathrm{min}$; injector temperature: $360^{\circ} \mathrm{C}$; detector temperature: $375{ }^{\circ} \mathrm{C}$; injected volume: $1.0 \mathrm{~mL}$; sample 
concentration: $100 \mathrm{mg}$ in $5 \mathrm{~mL}$ of tetrahydrofurane. TAG groups were identified by comparing retention times, following the procedures of Antoniosi Filho et al. (1995). The analyses were performed in duplicate for each sample.

Regiospecificdistribution. Nuclear magnetic resonance spectroscopy, the high-resolution carbon-13 $\left({ }^{13} \mathrm{C}\right.$ RMN) of acyl chains of TAGs was used as a quantitative method for the regiospecific analysis of cocoa butter samples (Silva et al., 2010). The analyses were performed in a Bruker Advance DPX 300 Nuclear Magnetic Resonance spectrometer (RMN)(Silberstreifen, Rheinstetten, Germany). The determination of ${ }^{13} \mathrm{C}$ was made at 75.8 $\mathrm{MHz}$ frequency with a $5 \mathrm{~mm}$-multi nuclear probe operating at $30{ }^{\circ} \mathrm{C}$, according to Vlahov's methodology (Vlahov, 1998; Vlahov, 2005). Results are given as saturated, oleic and linoleic fatty acid composition at sn-2 e sn-1,3 positions of TAGs. Analyses were performed in triplicate.

Melting point. The melting temperature was determined in duplicate for each sample, using an open capillary tube, according to AOCS procedures, Cc 3-25 Method (AOCS, 2004). Analyses were performed in triplicate.

Solid fat content. Solid fat content profiles were determined using Nuclear Magnetic Resonance (NMR) spectrometry (Bruker pc120 Minispec, Silberstreifen, Rheinstetten, Germany) and TCON 2000 high precision dry baths $\left(0-70^{\circ} \mathrm{C}\right)$ (Duratech, Carmel,USA), according to the AOCS Cd 16b-93 method: direct method, sample reading in series at temperatures of $10,15,20,25,30,35$ and $40{ }^{\circ} \mathrm{C}$, with tempering for cocoa butterand/or special fats (AOCS, 2004). The analyses were performed in duplicate for each sample.

Consistency. The consistency was determined with the TA-XT Plus Texture Analyzer equipment (Stable Micro Systems, Surrey, UK), controlled by a microcomputer. The samples were warmed an oven at $60^{\circ} \mathrm{C}$, to completely melt the crystals, then placed in beakers of $50 \mathrm{~mL}$. Conditioning was performed in an incubator for 24 hours at $5{ }^{\circ} \mathrm{C}$ to induce cocoa butter crystallization and then for 24 hours at temperature readings: 20,25 and $30^{\circ} \mathrm{C}$. An acrylic cone with an apex angle of $60^{\circ}$ and no truncation was used in the experiments. Tests were operated in the following conditions: displacement in the sample equal to $10 \mathrm{~mm}$; probe velocity of 2 $\mathrm{mm} / \mathrm{s}$; penetration time of $5 \mathrm{~s}$ (Campos, 2005; Rodrigues et al., 2007). From these conditions, compressive force in $g_{f}$ was obtained. Penetration data were converted into yield value, according to Haighton (1959):

$$
C=\frac{K \times W}{p^{1,6}}
$$

Where: $\mathrm{C}=$ yield value, in $\mathrm{g}_{\mathrm{f}} / \mathrm{cm}^{2} ; \mathrm{K}=$ factor depending on cone angle (equal to 2815 for a cone of $\left.60^{\circ}\right) ; \mathrm{W}=$ compression force in $\left(g_{\mathrm{f}}\right) ; \mathrm{p}=$ penetration depth $(\mathrm{mm} / 10)$. Samples were analyzed in triplicate and the results correspond to the calculated average.

\subsection{Statistics Analysis}

The statistical analyses were based on the Analysis of variance (ANOVA) and TukeyTest to determine the significant differences of the means at a probability level of $5 \%(p<0.05)$ using Statistica 8.0 (Statsoft, USA).

\section{RESULTS AND DISCUSSION}

\subsection{Fatty acid composition}

Table 1 shows the fatty acid composition obtained for all six cocoa butter samples. The results express the average of two determinations and are in accordance with the limits found in the literature, which indicate the following characteristic range for palmitic, stearic and oleic acids: $24-27 \%$, $34-36 \%$ and $32-35 \%$, respectively (Subramaniam, 2000; Awad and Marangoni, 2006; Gunstone and Harwood, 2007). These fatty acids were the predominant species in all samples, with the total varying from 93.4 to $95.2 \%$. According to Shukla (2006), differences in fatty acid composition of cocoa butter can result in iodine values varying from 34 to 40 . Therefore, the observed values for the analyzed samples are in agreement with the technical literature. Blend $\mathrm{C}$ showed the highest amount of saturated fatty acids (63.9\%), while the lowest content was verified for Braz C sample (62.4\%).

The different samples presented similar contents of each fatty acid. In general, Brazilian cocoa butter samples showed slightly superior contents of oleic and linoleic acids compared to the values found for the industrial blends. In a detailed study, Lipp et al. (2001) characterized the fatty acid composition of cocoa butter samples originating from several countries. South American cocoa butter presented linoleic acid contents higher than $3 \%$; Asian cocoa butter showed percentages inferior to $2.5 \%$ and African samples had values between these two limits. The authors emphasized that very small differences, particularly with respect to the linoleic acid content, reflect the geographical origin of the cocoa butter. This information corroborates the current study. The lower percentages of linoleic acid obtained for the blends are possibly due to the mixtures of cocoa butter from other countries.

In accordance with the literature, Braz B and Braz C samples presented the lowest percentages of palmitic acid among the samples, which attributes a lower content of this fatty acid to Brazilian cocoa butter when compared to cocoa butter produced in Ghana, The Ivory Coast and Malaysia (Gunstone and Harwood, 2007). 
Table 1

Fatty acid composition (\%) of the cocoa butter samples

\begin{tabular}{lrrrrrr}
\hline \multicolumn{1}{c}{ Fatty acid (\%) } & Blend A & Blend B & Blend C & Braz A & Braz B & Braz C \\
\hline C14:0 - myristic & $0.1 \pm 0.0$ & $0.1 \pm 0.0$ & $0.1 \pm 0.0$ & $0.1 \pm 0.0$ & $0.1 \pm 0.0$ & $0.1 \pm 0.0$ \\
C16:0 - palmitic & $25.8 \pm 0.1$ & $25.3 \pm 0.1$ & $26.7 \pm 0.0$ & $25.6 \pm 0.2$ & $24.3 \pm 0.1$ & $24.8 \pm 0.0$ \\
C16:1 - palmitoleic & $0.3 \pm 0.0$ & $0.3 \pm 0.0$ & $0.3 \pm 0.0$ & $0.3 \pm 0.0$ & $0.2 \pm 0.0$ & $0.3 \pm 0.0$ \\
C17:0 - margaric & $0.2 \pm 0.0$ & $0.2 \pm 0.0$ & $0.2 \pm 0.0$ & $0.2 \pm 0.0$ & $0.3 \pm 0.0$ & $0.3 \pm 0.0$ \\
C18:0 - stearic & $35.6 \pm 0.3$ & $36.1 \pm 0.3$ & $35.6 \pm 0.1$ & $35.3 \pm 0.2$ & $35.4 \pm 0.4$ & $35.1 \pm 0.1$ \\
C18:1- - oleic & $33.4 \pm 0.1$ & $33.5 \pm 0.1$ & $33.0 \pm 0.2$ & $33.9 \pm 0.2$ & $33.7 \pm 0.3$ & $33.9 \pm 0.2$ \\
C18:2 - linoleic & $3.0 \pm 0.1$ & $2.9 \pm 0.1$ & $2.7 \pm 0.0$ & $3.1 \pm 0.1$ & $3.2 \pm 0.0$ & $3.2 \pm 0.1$ \\
C18:3 - linolenic & $0.2 \pm 0.0$ & $0.2 \pm 0.0$ & $0.2 \pm 0.0$ & $0.2 \pm 0.0$ & $0.2 \pm 0.0$ & $0.2 \pm 0.0$ \\
C20:0 - arachidic & $1.1 \pm 0.0$ & $1.2 \pm 0.0$ & $1.2 \pm 0.0$ & $1.1 \pm 0.0$ & $2.1 \pm 0.1$ & $1.8 \pm 0.1$ \\
C20:1 - gadoleic & - & - & - & - & $0.1 \pm 0.0$ & $0.1 \pm 0.0$ \\
C22:0 - behenic & $0.2 \pm 0.0$ & $0.2 \pm 0.0$ & $0.2 \pm 0.0$ & $0.2 \pm 0.0$ & $0.4 \pm 0.0$ & $0.3 \pm 0.0$ \\
C24:0 - lignoceric & $0.1 \pm 0.0$ & $0.1 \pm 0.0$ & - & - & $0.1 \pm 0.0$ & $0.1 \pm 0.0$ \\
\hline$\Sigma$ Saturated & $63.1 \pm 0.0^{\mathrm{a}}$ & $63.2 \pm 0.0^{\mathrm{a}}$ & $63.9 \pm 0.1^{\mathrm{b}}$ & $62.6 \pm 0.0^{\mathrm{c}}$ & $62.6 \pm 0.0^{\mathrm{c}}$ & $62.4 \pm 0.0^{\mathrm{d}}$ \\
$\Sigma$ Unsaturated & $36.9 \pm 0.1^{\mathrm{a}}$ & $36.8 \pm 0.0^{\mathrm{a}}$ & $36.1 \pm 0.1^{\mathrm{b}}$ & $37.4 \pm 0.1^{\mathrm{c}}$ & $37.4 \pm 0.1^{\mathrm{c}}$ & $37.6 \pm 0.1^{\mathrm{d}}$ \\
\hline
\end{tabular}

-: not detected. Means \pm standard deviation of the replications. Means followed by the same letter within a line indicate significant difference $(p<0.05)$ by Tukey's test.

The percentages of saturated and unsaturated fatty acids, for samples Blend $A$ and Blend $B$ and for samples Braz A e Braz B showed no significant difference $(p<0.05)$ among themselves, according to the Tukey Test.

\subsection{Triacyglycerol composition}

More recent studies on the variation of the chemical compositions of cocoa butter have been focused on TAG composition analyses (Timms, 2003). The results obtained for the six samples are shown in Table 2. For Brazilian samples, 12 different TAGs were found. The industrial blends indicated the presence of 11 TAG species, since POL was not detected. POP, POSt and StOSt were predominant, ranging from 79.8 to $87.4 \%$ of the total TAG composition, in accordance with literature information, which indicates a range of 80 to $85 \%$ for these symmetrical compounds of saturatedunsaturated-saturated type (Norberg, 2006; Lipp et al., 2001). The main asymmetrical TAGs were the PStSt, POO and StOO species.

The industrial blends showed more POP and POSt than the Brazilian samples, although StOO contents were higher in the national samples. According to Lipp and Anklam (1998), higher percentages of $\mathrm{POO}$ and StOO characterize a cocoa butter of superior softness. Higher POO and POL percentages, particularly, were observed for the Braz C sample from Espírito Santo. Since these TAGs correspond to two out of three species of major unsaturation degrees found in cocoa butter samples, it is possible to assume that this peculiarity in its chemical composition favors differentiated solidification behavior compared to the other samples.
Considering only the TAG species of "saturated fatty acid - oleic acid - saturated fatty acid" type, the Brazilian samples contained percentages ranging from 81.3 to $85.2 \%$; for the blends, these values lay between 87.1 and $88.5 \%$. According to Gunstone and Harwood (2007), this parameter can be used as an indication of the cocoa butter origin and the values presented in Table 2 indicate lower amounts in Brazilian raw materials.

In general, the physical properties of a fat are more easily interpreted using the classification of the TAGs in groups according to their unsaturation degree: $S_{3}$ (trisaturated), $S_{2} U$ (disaturated-monounsaturated), $\mathrm{U}_{2} \mathrm{~S}$ (monounsaturated-diunsaturated) and $U_{3}$ (triunsaturated), instead of the individual TAG species (Neff et al., 2001). For all cocoa butter samples studied, $\mathrm{S}_{3}, \mathrm{~S}_{2} \mathrm{U}$ and $\mathrm{U}_{2} \mathrm{~S}$ types were found, but no $U_{3}$ was detected. The origin of the samples of cocoa butter show to be statistically significant $(p<0.05)$ for the different classes of triacylglycerols, according to Table 2 .

$\mathrm{S}_{3}$ varied from 1.4 to $3.1 \%$ among all the samples, in accordance to published data for cocoa butter of different origins (Loisel et al., 1998). Higher $S_{2} \cup$ contents were observed for the industrial blends while Brazilian samples were characterized by higher percentages of $\mathrm{U}_{2} \mathrm{~S}$ (from 6.8 to $10.3 \%$ ), due to the major contributions of POO, POL and StOO species. Lonchampt and Hartel (2004) and Shukla (2006), analyzing cocoa samples from different origins, found that Brazilian cocoa butter showed the highest content of $\mathrm{U}_{2} \mathrm{~S}$, which corroborates the results here presented and also confirms that cocoa butter from other countries were used in the production of the industrial standard blends. 
Table 2

Triacylglycerol (TAG) composition (\%) of samples, for individual TAGs and TAG classes

\begin{tabular}{lrrrrrr}
\hline TAG (\%) & \multicolumn{1}{c}{ Blend A } & \multicolumn{1}{c}{ Blend B } & \multicolumn{1}{c}{ Blend C } & \multicolumn{1}{c}{ Braz A } & \multicolumn{1}{c}{ Braz B } & \multicolumn{1}{c}{ Braz C } \\
\hline PPSt & $0.2 \pm 0.0$ & $0.9 \pm 0.1$ & $0.9 \pm 0.0$ & $0.9 \pm 0.0$ & $0.2 \pm 0.0$ & $0.5 \pm 0.0$ \\
POP & $20.0 \pm 0.2$ & $17.3 \pm 0.2$ & $21.6 \pm 0.5$ & $19.0 \pm 0.1$ & $18.4 \pm 0.2$ & $17.3 \pm 0.0$ \\
PLP & $2.2 \pm 0.1$ & $1.7 \pm 0.0$ & $2.0 \pm 0.1$ & $2.3 \pm 0.1$ & $1.9 \pm 0.0$ & $1.6 \pm 0.1$ \\
PStSt & $1.6 \pm 0.2$ & $0.5 \pm 0.0$ & $2.2 \pm 0.1$ & $1.9 \pm 0.3$ & $0.4 \pm 0.0$ & $1.6 \pm 0.1$ \\
POSt & $43.8 \pm 0.2$ & $41.5 \pm 0.1$ & $43.1 \pm 0.2$ & $41.2 \pm 0.2$ & $39.4 \pm 0.3$ & $40.8 \pm 0.4$ \\
POO & $3.2 \pm 0.1$ & $3.0 \pm 0.0$ & $3.4 \pm 0.1$ & $4.7 \pm 0.3$ & $2.1 \pm 0.0$ & $5.2 \pm 0.2$ \\
PLSt & $3.7 \pm 0.0$ & $3.1 \pm 0.1$ & $3.4 \pm 0.1$ & $2.9 \pm 0.0$ & $2.6 \pm 0.0$ & $4.2 \pm 0.2$ \\
POL & - & - & - & $0.3 \pm 0.0$ & $0.3 \pm 0.0$ & $0.9 \pm 0.0$ \\
StOSt & $22.8 \pm 0.3$ & $26.6 \pm 0.3$ & $21.4 \pm 0.4$ & $21.5 \pm 0.6$ & $27.2 \pm 0.5$ & $21.7 \pm 0.2$ \\
StOO & $1.5 \pm 0.0$ & $2.9 \pm 0.2$ & $1.0 \pm 0.0$ & $3.8 \pm 0.1$ & $4.3 \pm 0.1$ & $4.1 \pm 0.1$ \\
StLSt & - & $1.4 \pm 0.0$ & - & $1.2 \pm 0.0$ & $2.0 \pm 0.0$ & $0.6 \pm 0.0$ \\
StOA & $1.0 \pm 0.0$ & $1.1 \pm 0.1$ & $1.1 \pm 0.0$ & $0.3 \pm 0.0$ & $1.3 \pm 0.0$ & $1.5 \pm 0.1$ \\
\hline$\Sigma \mathrm{S}_{3}$ & $1.8 \pm 0.1^{\mathrm{a}}$ & $1.4 \pm 0.1^{\mathrm{b}}$ & $3.1 \pm 0.1^{\mathrm{c}}$ & $2.8 \pm 0.0^{\mathrm{d}}$ & $1.6 \pm 0.0^{\mathrm{e}}$ & $2.0 \pm 0.0^{\mathrm{f}}$ \\
$\Sigma \mathrm{S}_{2} \mathrm{U}$ & $94.5 \pm 0.1^{\mathrm{a}}$ & $94.8 \pm 0.2^{\mathrm{b}}$ & $93.0 \pm 0.4^{\mathrm{c}}$ & $88.4 \pm 0.4^{\mathrm{d}}$ & $91.7 \pm 0.5^{\mathrm{e}}$ & $87.7 \pm 0.4^{\dagger}$ \\
$\Sigma \mathrm{U}_{2} \mathrm{~S}$ & $3.7 \pm 0.0^{\mathrm{a}}$ & $3.9 \pm 0.0^{\mathrm{b}}$ & $3.8 \pm 0.3^{\mathrm{c}}$ & $8.8 \pm 0.1^{\mathrm{d}}$ & $6.8 \pm 0.4^{\mathrm{e}}$ & $10.3 \pm 0.2^{\dagger}$ \\
\hline
\end{tabular}

$\mathrm{P}=$ palmitic, $\mathrm{St}=$ stearic, $\mathrm{O}=$ oleic, $\mathrm{L}=$ linoleic and $\mathrm{A}=$ arachidic acids. $\mathrm{S}_{3}=$ trisaturated,

$\mathrm{S}_{2} \mathrm{U}=$ disaturated-monounsaturated and $\mathrm{U}_{2} \mathrm{~S}=$ monounsaturated-diunsaturated triacylglycerols. -: not detected.

Means \pm standard deviation of the replications. Means followed by the same letter within a line indicate significant difference $(p<0.05)$ by Tukey's test.

$\mathrm{U}_{2} \mathrm{~S}$, with melting points between 27 and $42{ }^{\circ} \mathrm{C}$, are responsible for the structuring of the products containing cocoa butter as the fat base. The contribution of $\mathrm{U}_{2} \mathrm{~S}$ is also important when considering their sensorial properties at room temperature. As a consequence, the ratio between $\mathrm{S}_{2} \mathrm{U}$ and $\mathrm{U}_{2} \mathrm{~S}$ amounts in cocoa butter is selectively associated with an increase in thetechnological functionality or improved ability of the sensorial attributes of this raw-material (Bessler and Orthoefer, 1983). According to Lipp and Anklam (1998), cocoa butter with lower $S_{2} U$ contents and higher $U_{2} S$ levels, as for example the Brazilian samples evaluated in this study, can lead to unsatisfactory crystallization characteristics. However, the technical literature does not indicate the limits of these TAG classes suitable for adequate crystallization behavior in different climate regions.

\subsection{Regiospecific distribution}

A detailed knowledge of the chemical composition of cocoa butter should also contemplate the determination of the regiospecific distribution of the TAGs, which pinpoints the fatty acid substitution in the three positions of the glycerol chain, recognized as sn-2 and sn-1,3 (Segall et al., 2005). The method is based on the detection of resonances of the carbonyl carbon groups of the fatty acids in the TAG molecule (Jie and Mustafa, 1997; Vlahov, 1998; Silwood and Grootveld, 1999).

The fatty acid distribution at the sn-2 and sn-1,3 positions of the cocoa butter samples are shown in
Table 3. One of the most peculiar composition characteristics of cocoa butter is the major presence of 2-oleyl-glycerol TAGs of palmitic and stearic acids, which occur as symmetrical molecules containing one unsaturated fatty acid at the central position. Information on quantitative differences in this distribution, for the same kind of sample, is rarely found in the literature (Segall et al., 2005; Wang et al., 2006). The results in Table 3 indicate that, for cocoa butter, the sn-2 position is predominantly characterized by thepresence of unsaturated fatty acids, especially oleic (C18:1) and linoleic (C18:2) acids. The method did not detect any saturated fatty acid for this position. A hypothesis to be considered in this case is that the method of analysis by ${ }^{13} \mathrm{C}$ RMN is not sensitive enough to detect small amounts of saturated fatty acids. Oleic acid percentages for this position varied from 86.4 to $91.7 \%$, and ranged from 8.3 to $13.6 \%$ for linoleic acid. The highest percentages of linoleic acid were observed for two national samples (Braz A and Braz B). For blends, however, these contents were similar. For the $s n-1,3$ positions, the presence of saturatec fatty acid was dominant, ranging from 91.7 to $96.1 \%$, and can be assigned to the sum of palmitic and stearic acids, according to Tables 1 and 2. Small contents of oleic acid were also observed in the $s n-1,3$ position, but linoleic acid was not detected. These findings confirm the TAG composition given in Table 2 , where this fatty acid was found in very small amounts (Brazilian samples) or not detected at all (blends) at these positions in the TAGs. All samples were statistically 
Table 3

Fatty acid distribution (\%) at sn-2 e sn-1,3 positions of triacylglycerols, for the cocoa butter samples

\begin{tabular}{lcrcc}
\hline \multirow{2}{*}{ Sample } & \multicolumn{2}{c}{ sn - 2(\%) } & \multicolumn{2}{c}{ sn -1,3 (\%) } \\
\cline { 2 - 5 } & C 18:1 & \multicolumn{1}{c}{ C18:2 } & Saturated & C18:1 \\
\hline Blend A & $91.0 \pm 0.5^{\mathrm{a}}$ & $9.0 \pm 0.5^{\mathrm{a}}$ & $95.4 \pm 0.4^{\mathrm{a}}$ & $4.6 \pm 0.4^{\mathrm{a}}$ \\
Blend B & $91.7 \pm 0.1^{\mathrm{b}}$ & $8.3 \pm 0.1^{\mathrm{b}}$ & $96.1 \pm 0.1^{\mathrm{b}}$ & $3.9 \pm 0.2^{\mathrm{b}}$ \\
Blend C & $90.4 \pm 0.0^{\mathrm{a}}$ & $9.6 \pm 0.1^{\mathrm{c}}$ & $93.6 \pm 0.1^{\mathrm{c}}$ & $6.4 \pm 0.1^{\mathrm{c}}$ \\
Braz A & $86.4 \pm 0.0^{\mathrm{c}}$ & $13.6 \pm 0.0^{\mathrm{d}}$ & $91.7 \pm 0.0^{\mathrm{d}}$ & $8.3 \pm 0.0^{\mathrm{d}}$ \\
Braz B & $91.1 \pm 0.1^{\mathrm{b}}$ & $8.9 \pm 0.2^{\mathrm{a}}$ & $94.6 \pm 0.3^{\mathrm{e}}$ & $5.4 \pm 0.4^{\mathrm{e}}$ \\
Braz C & $89.6 \pm 0.1^{\mathrm{d}}$ & $10.4 \pm 0.1^{\mathrm{e}}$ & $95.8 \pm 0.1^{\mathrm{f}}$ & $4.2 \pm 0.1^{\mathrm{f}}$ \\
\hline
\end{tabular}

Means \pm standard deviation of the replications. Means followed by the same letter within a column indicate significant difference $(p<0.05)$ by Tukey's test.

distinguishable $(p<0.05)$ in term of the distribution of fatty acids at the $s n-1,3$ position, confirming the statistical results presented in Table 2.

Although studies on the regiospecific distribution of cocoa butter are scarce in scientific literature, the findings obtained in the present study show agreement with the results published by Takagi and Ando (1995), through chiral phase liquid chromatography. They found oleic and linoleic acid percentages equal to 87.5 and $7.4 \%$, respectively for the $s n-2$ position. For the $s n-1,3$ positions, the saturated fatty acid content corresponded to $95.3 \%$, while for oleic acid a content of $3.9 \%$ was found. Unfortunately, the authors did not report on the origin of the cocoa butter evaluated. Kosugi et al. (2004) reported a collaborative action among laboratories to study the regiospecific distribution of cocoa butter, using several lipases. For the $s n-2$ position, linoleic acid contents ranged from 7.9 to $10.0 \%$; for oleic acid, the values varied from 81.6 to $86.9 \%$, close to the results obtained in the present study. The use of ${ }^{13} \mathrm{C}$ NMR spectroscopy, therefore, proved to be an effective tool for the determination of the regiospecific distribution of cocoa butter TAGs, and in combination with the TAG composition found, it allowed researchers to validate 1,3-dipalmitoyl-2-oleoylglycerol (POP), 1-palmitoyl-2-oleoyl-3-stearoylglycerol (POSt) and 1,3-diestearoil-2-oleoyl-glycerol (StOSt) as the main TAGs in cocoa butter.

\subsection{Melting point}

According to Shukla (2006), cocoa butter is characterized by a narrow melting temperature range (32 to $35^{\circ} \mathrm{C}$ ) due to its relatively uniform chemical compo- sition. The melting points determined for the six samples are presented in Table 4. Values varied from 33.0 to $33.4^{\circ} \mathrm{C}$ for the Brazilian cocoa butter samples and were higher for the blends (34.3 to $34.6^{\circ} \mathrm{C}$ ). The sample Blend $\mathrm{C}$ showed no significant difference $(\mathrm{p}<$ 0.05) compared to the other samples of blends. Among the Brazilian samples, only sample Braz $\mathrm{C}$ differed statistically $(p<0.05)$ from the others in relation to the melting point.

These results show good correlation with the behavior expected from the TAG compositions (Table 2). The mathematical relationships between the melting point and the levels of $S_{2} U$ and $U_{2}$ STAGs for the samples were linear and given by the equations: $\mathrm{S} \mathrm{S}_{2} \mathrm{U}(\%)=4.1483^{*} \mathrm{mp}\left({ }^{\circ} \mathrm{C}\right)-48.666$; $\mathrm{R}^{2}=0.8574 ;$ and $\mathrm{S} \mathrm{U}_{2} \mathrm{~S}(\%)=-4.0785^{\star} \mathrm{mp}\left({ }^{\circ} \mathrm{C}\right)$ $+144.21 ; R^{2}=0.9253$; where $\mathrm{mp}=$ melting point.

$\mathrm{S}_{2} \mathrm{U}$, was represented mainly by the POP, POSt and StOSt species, which have melting points from 35.3 to $41.2^{\circ} \mathrm{C}$. The melting point of $U_{2} S$ triacylglycerols, however, is significantly lower. For the StOO and POO species, which make up almost all of this TAG class in the evaluated samples, the melting points are, respectively, 23.7 and $19.2{ }^{\circ} \mathrm{C}$, so that these components are liquid at room temperature (Bockisch, 1998). The increase in $U_{2} \mathrm{~S}$ triacyglycerol contents, therefore, contributes to a decrease in the melting point of cocoa butter. The melting points for the Brazilian samples are lower, according to the increase in the percentage of the $\mathrm{U}_{2} \mathrm{~S}$ class. Braz A, Braz $B$ and Braz $C$ samples, with melting points of 33.3 ; 33.4 and $33.0{ }^{\circ} \mathrm{C}$, showed $\mathrm{U}_{2} \mathrm{~S}$ contents equal to 8.8; 6.8 and $10.3 \%$, respectively. Likewise, the industrial blends with $\mathrm{U}_{2} \mathrm{~S}$ percentages varying from 3.7 to $3.9 \%$ showed

Table 4

Melting point $\left({ }^{\circ} \mathrm{C}\right)$ of the cocoa butter samples

\begin{tabular}{cccccc}
\hline \multicolumn{5}{c}{ Melting point $\left({ }^{\circ} \mathbf{C}\right)$} \\
\hline Blend A & Blend B & Blend C & Braz A & Braz B & Braz C \\
\hline $34.3 \pm 0.1^{\mathrm{a}}$ & $34.6 \pm 0.1^{\mathrm{b}}$ & $34.4 \pm 0.1^{\mathrm{a}, \mathrm{b}}$ & $33.3 \pm 0.0^{\mathrm{c}}$ & $33.4 \pm 0.3^{\mathrm{c}}$ & $33.0 \pm 0.0^{\mathrm{d}}$ \\
\hline
\end{tabular}

Means \pm standard deviation of the replications. Means followed by the same letter within a line indicate significant difference $(p<0.05)$ by Tukey's test. 
thehighest melting points, since these samples also have lower contents of TAGs with a lower melting point. The better technological performance of the industrial blends, in comparison to the cocoa butter produced in Brazil, can be attributed to this characteristic. The chocolates produced with the blend show superior thermal resistance, required in regions of hotter climates and with temperature fluctuations during storage and transportation.

\subsection{Solid fat content}

The solid fat content (SFC) is a parameter that expresses the solid/liquid mass relation of a fat at different temperatures, affecting physical properties like consistency and stability and also important sensorial attributes (Beckett, 2008). Figure 1 presents the solid curves of cocoa butter samples and two distinct behaviors can be distinguished. All the industrial blends and the sample Braz B, showed very similar solid profiles. At $10^{\circ} \mathrm{C}$, the SFC of these samples corresponded to $85.4 ; 84.5 ; 83.9$ and $82.5 \%$, for Blend C, Blend A, Blend B and Braz B samples, respectively. Braz $A$ and Braz $C$ samples were characterized by lower SFC values, and at $10^{\circ} \mathrm{C}$ they were $77.4 \%$ (Braz A) and 76.6\% (Braz C). At $25{ }^{\circ} \mathrm{C}$, the SFC for the first group ranged from 58.9 to $64.7 \%$; for Braz A and Braz C samples, however, the SFC was $53.7 \%$ and $52.3 \%$, respectively. At this temperature, regarding the SFC values, only the samples Blend A and Blend B did not differ statistically from one another $(p<0.05)$.

In general, the SFC values at a specific temperature for this fat increase according to $S_{2} U$ levels, the predominant TAG class in cocoa butter (Shukla, 2006). This correlation could explain the differences found for Braz $A$ and Braz $C$ samples, which had $\mathrm{S}_{2} \mathrm{U}$ contents lower than $90 \%$. Blend $\mathrm{C}$ had a lower $S_{2} U$ content compared to Blend $A$ and Blend $B$, the later with higher SFC. Since this sample presented a high content of $\mathrm{S}_{3}(3.1 \%)$, represented by the PPSt and PStSt species, with melting points significantly higher $\left(62.9\right.$ and $65.2^{\circ} \mathrm{C}$, respectively), which could justify their superior hardness (Bockisch, 1998). Considering only the Brazilian cocoa butters, the Braz B sample from Amazonas State was the only one that showed a solid profile similar to the blends used as an industrial standard in Brazil. This superior hardness for Braz B can be a consequence of its high $\mathrm{S}_{2} \mathrm{U}$ content compared to the other Brazilian samples, according to Table 2. An increase of only 0.7 and $0.9 \%$ in oleic and linoleic acid contents can be related to a decrease of approximately $10 \%$ in the SFC value at $25^{\circ} \mathrm{C}$, a result that was also found by Timms (2003).

Shukla's (2006) studies showed that, at $25^{\circ} \mathrm{C}$, the SFC of the cocoa butter samples from Ghana, India, Nigeria, Ivory Coast, Malaysia and Sri Lanka presented variations from 74.8 to $83.7 \%$, while for Brazilian cocoa butter, this percentage was significantly lower (Shukla, 2006). He found an SFC of $53.3 \%$, close to the values determined for the Brazilian samples in this work. Similar observation was reported by Beckett (2008)and by Yamada et al. (2005), when comparing cocoa butter properties from different countries. According to Subramaniam (2000), the use of raw material with an excess of liquid fat can undermine the stability of chocolate and analogous products during storage. Therefore, the solid curves obtained for Braz A and Braz $C$ samples in this study confirm that national

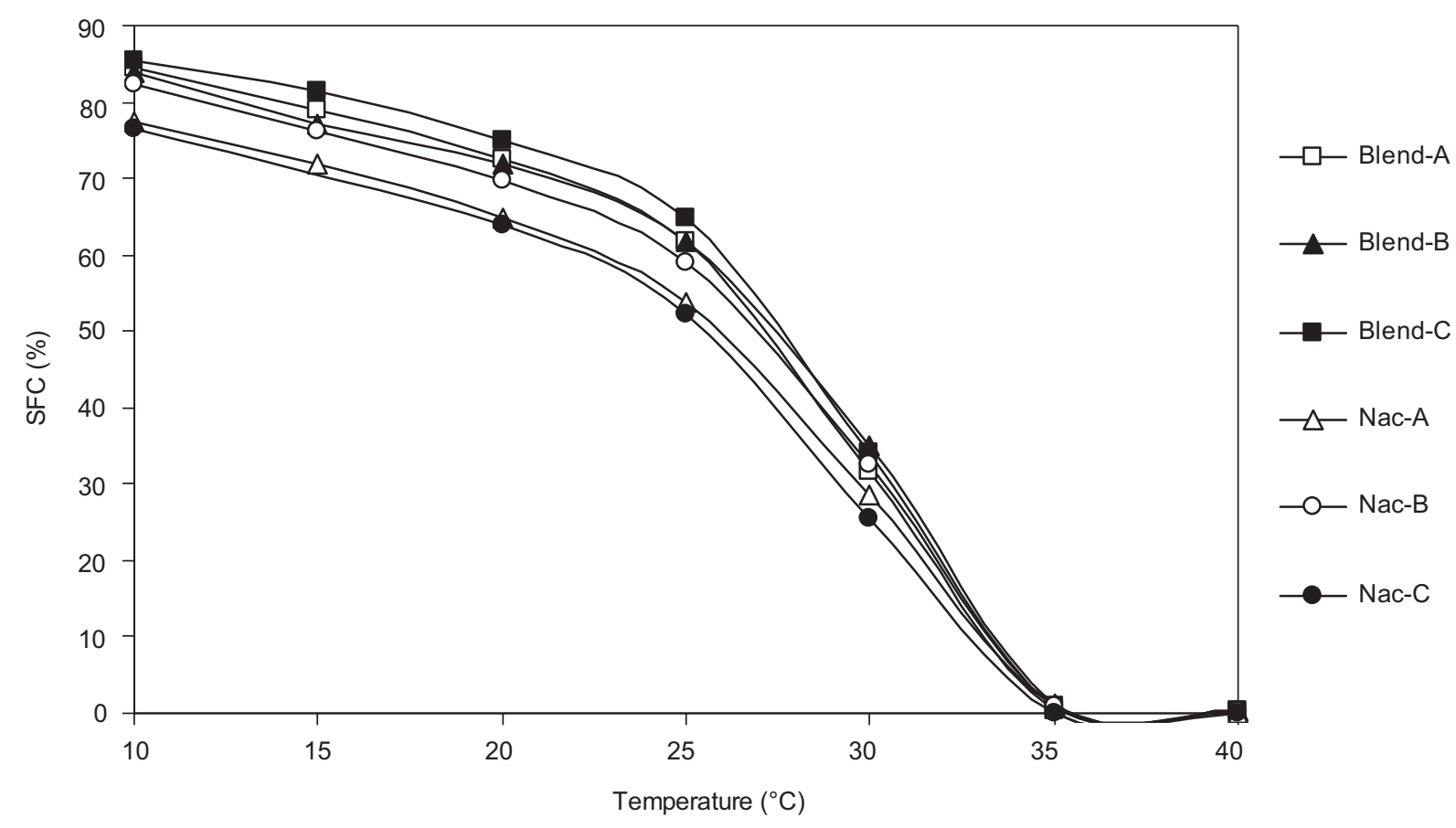

Figure. 1

Solid fat content profiles of the cocoa butter samples. 
cocoa butter is considered a softer raw material and needs to be added to the cocoa butter of other origins to confer high SFC at several temperatures, when used in tropical regions.

The solid curve provides indications about the technological performance of cocoa butter. An SFC between 20 and $25{ }^{\circ} \mathrm{C}$ qualifies the cocoa butter hardness. The temperature range in which an expressive decline in SFC is evident represents the heating resistance, while the fast melting between 32 and $35^{\circ} \mathrm{C}$ is responsible for cooling and creaminess sensation during tasting (Beckett, 2008). One of the more important and practical parameters used in the industry for evaluating cocoa butter quality is the difference between the SFC at 25 and $35{ }^{\circ} \mathrm{C}$ (named $\Delta S$ ). The presence of solid fat at temperatures above $35{ }^{\circ} \mathrm{C}$ is recognized as a waxy feeling and is easily detected during tasting. So, in order for cocoa butter to be used in chocolate manufacturing in tropical climates, it should be hard and brittle at room temperature (SFC higher than $50 \%$ at $25^{\circ} \mathrm{C}$ ) and present good melting properties in the mouth (high $\Delta S$ value), and no waxy residual (no SFC above $35^{\circ} \mathrm{C}$ ) (Luccas, 2001). Considering these requirements, all samples meet the hardness requirements for use in warm climates, due to their SFC values at $25{ }^{\circ} \mathrm{C}$. The $\Delta S$ values found are $61.2 ; 60.6 ; 63.8 ; 52.9 ; 58.1$ and $52.2 \%$, for Blend A, Blend B, Blend C, Braz A, Braz B and Braz $\mathrm{C}$ samples, respectively. The higher $\Delta \mathrm{S}$ values found for the industrial blends ensure adequate melting properties at body temperature. The evaluated samples showed no waxy residual, and therefore proved to be appropriate regarding the sensory attributes.

\subsection{Consistency}

According to Gunstone and Harwood (2007), cocoa butter is hard and brittle at $20^{\circ} \mathrm{C}$, turning soft between 30 and $32{ }^{\circ} \mathrm{C}$. Consistent data for the six cocoa butter samples are presented in Table 5 as a function of the temperature, represented as yield value $\left(\mathrm{g}_{\mathrm{f}} / \mathrm{cm}^{2}\right)$. Consistency of the samples diminished substantially with the increase in temperature, due to gradual crystal melting and consequent destruction of the crystalline network, conferring plasticity to cocoa butter (Deman, 1983).

According to Haighton (1959), a fat is considered as "very hard" when its yield value is above $1500 \mathrm{~g} / \mathrm{cm}^{2}$. The values in Table 5 indicate that at 20 and $25^{\circ} \mathrm{C}$, all cocoa butters are extremely hard and that at $20^{\circ} \mathrm{C}$, the hardness of the Brazilian samples is higher than the industrial blends. This behavior does not comply with the tendency found for the melting points and solid curves and should be attributed to the microstructural entanglement (crystal number, size and morphology) developed during the crystallization of these samples at this specific temperature (Campos et al., 2010). At $25{ }^{\circ} \mathrm{C}$, however, the yield values of the blends are two or three times the values measured for Brazilian cocoa butter, thus supporting for their preferential use in tropical climates.

At $30^{\circ} \mathrm{C}$, the Blend $A$ and Blend $B$ samples are still classified as "very hard", while Blend C and Braz B samples, with yield values between 1000 and $1500 \mathrm{~g}_{\mathrm{f}} / \mathrm{cm}^{2}$, can be considered as "hard and at the spreadability limit". Braz A and Braz C samples are qualified as "plastic and spreadable" raw material (Haighton, 1959). According to Jeyarani and Reddy (2005), fats scored as hard at room temperature are suitable ingredients for the manufacturing of food products with firm textures, like chocolate. The consistency values correlated well with the results obtained for the solid profiles for all the six samples. According to Beckett (2008), the relative hardness of cocoa butter is particularly affected by the $\mathrm{S}_{2} \mathrm{U} / \mathrm{U}_{2} \mathrm{~S}$ ratio, which corresponds to $25.7 ; 24.4 ; 24.6$; 10.0; 13.6 and 8.6, for Blend A, Blend B, Blend C, Braz A, Braz B and Braz C samples, respectively. The $\mathrm{S}_{2} \mathrm{U}$ contents, SFC values and yield values of the Brazilian samples presented a tendency to increase according to the average ambient temperature increase of the cultivation location in the sequence Espírito Santo, Bahia and Amazonas states. Lehrian et al. (1980) reported similar results in studies for cocoa butter obtained from trees cultivated in controlled microclimates. This kind of influence of environment conditions on vegetal oil and fat crop production has been extensively studied. In the

Table 5

Yield value $\left(\mathrm{g}_{\mathrm{f}} / \mathrm{cm}^{2}\right)$ of cocoa butter samples

\begin{tabular}{lccc}
\hline \multirow{2}{*}{ Sample } & \multicolumn{3}{c}{ Yield value $\left(\mathbf{g}_{\mathrm{f}} \mathbf{c m}^{\mathbf{2}}\right)$} \\
\cline { 2 - 4 } & $\mathbf{2 0}{ }^{\circ} \mathbf{C}$ & $\mathbf{2 5}{ }^{\circ} \mathbf{C}$ & $\mathbf{3 0}{ }^{\circ} \mathbf{C}$ \\
\hline Blend A & $17936.71 \pm 314.77^{\mathrm{a}}$ & $4106.10 \pm 188.11^{\mathrm{a}}$ & $1567.81 \pm 24.36^{\mathrm{a}}$ \\
Blend B & $14413.72 \pm 189.23^{\mathrm{b}}$ & $4999.24 \pm 251.28^{\mathrm{b}}$ & $1950.03 \pm 26.78^{\mathrm{b}}$ \\
Blend C & $15343.80 \pm 216.27^{\mathrm{c}}$ & $4594.72 \pm 175.55^{\mathrm{c}}$ & $1144.02 \pm 11.00^{\mathrm{c}}$ \\
Braz A & $20877.39 \pm 293.63^{\mathrm{d}}$ & $2307.48 \pm 142.57^{\mathrm{d}}$ & $557.44 \pm 64.93^{\mathrm{d}}$ \\
Braz B & $17484.23 \pm 180.85^{\mathrm{e}}$ & $2077.56 \pm 185.32^{\mathrm{e}}$ & $923.51 \pm 61.96^{\mathrm{e}}$ \\
Braz C & $19535.33 \pm 190.12^{\dagger}$ & $2505.35 \pm 160.88^{\mathrm{f}}$ & $737.55 \pm 20.06^{\mathrm{f}}$ \\
\hline
\end{tabular}

Means \pm standard deviation of the replications. Means followed by the same letter within a column indicate significant difference $(p<0.05)$ by Tukey's test. 


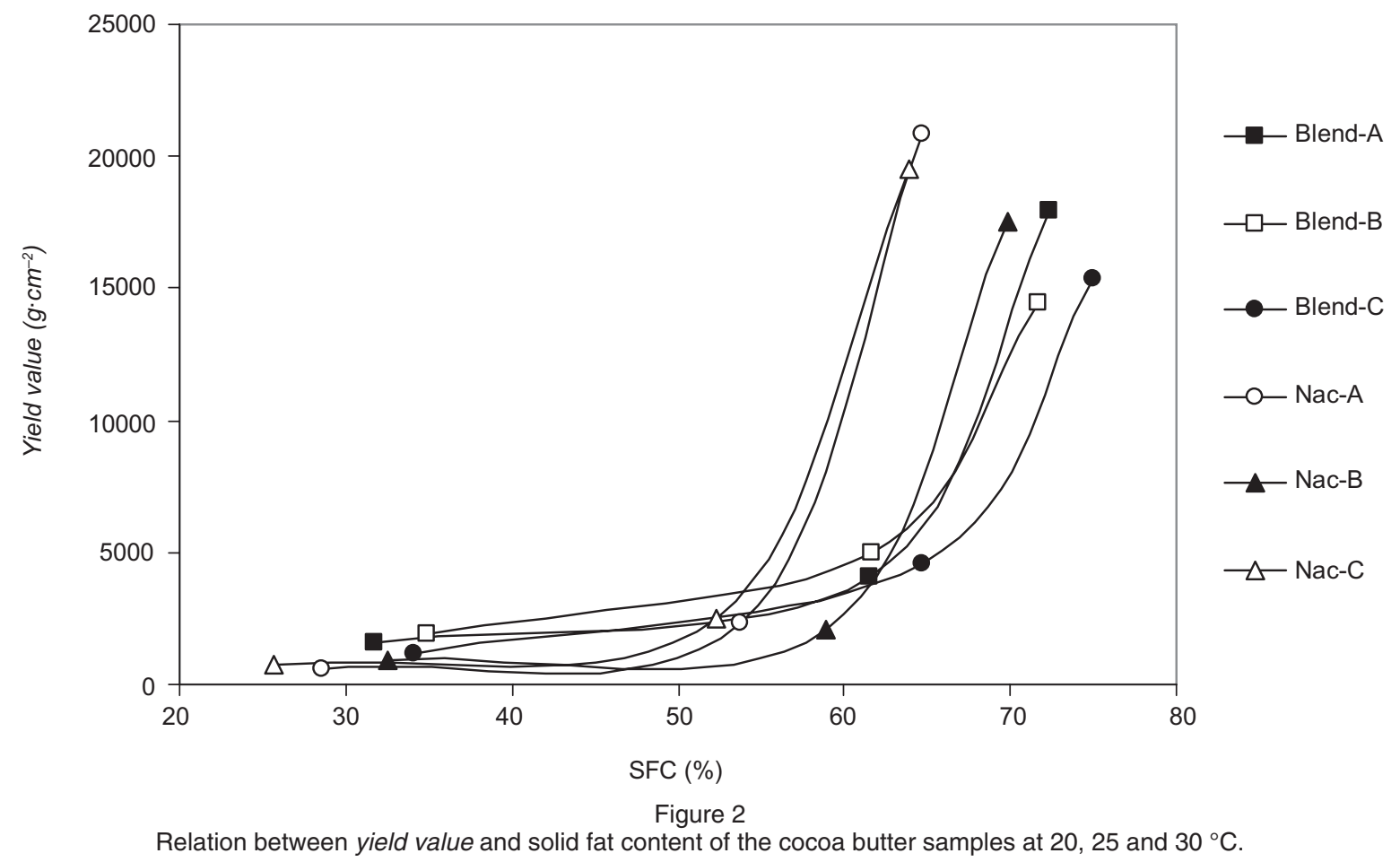

technical literature, there is a consensus that the closer to the equator the plant is cultivated, the lower the unsaturation degree and hardness of its fat components (Tucci et al., 1996).

Recent studies have investigated the relationships between solid profiles and consistency of fats. SFC is an important indicator of hardness in fats and can be used for predictive purposes (Ribeiro et al., 2009). Figure 2 presents the relationship between the yield value and SFC of the six cocoa butter samples at the temperatures corresponding to the consistency evaluation. It can be seen that the increase in consistency started at SFC values between 50 and $60 \%$. According to the solid profiles (Figure 1), this range corresponds to temperatures between 20 and $25^{\circ} \mathrm{C}$, limits usually set for cocoa butter hardness qualification (Gunstone and Harwood, 2007). A subsequent increase in SFC was reflected in an exponential increase in sample consistency, which can be attributed to the formation of a crystalline structure characterized by different structural levels related to individual TAGs, crystalline units and clusters (Shi et al., 2005).

\section{CONCLUSIONS}

The study on the chemical composition, solid fat content and consistency properties of Brazilian cocoa butter samples and industrial blends, used by Brazilian manufacturers and composed of cocoa butter from different countries, allowed for researchers to differentiate them according to their physicochemical characteristics and their potential use in industrial processes in tropical regions. In general, the blends exhibited more adequate attributes in terms of thermal resistance and hardness, which are necessary and compatible for their use under the different climate conditions of tropical regions. With regard to Brazilian samples, cocoa butter from the Amazonas State presented characteristics similar to the industrial blends, mainly the hardness profile. Cocoa butter from the Bahia and Espírito Santo States showed considerable softness that will give rise to technological problems when used in warm climates, thus justifying the requirement of blendingit with cocoa butter from other countries. In Part II of this study the same samples are evaluated for their crystallization kinetics, microstructure and polymorphism and the results are explained in terms of the chemical profile presented here.

\section{ACKNOWLEDGEMENTS}

To the Fundação de Amparo à Pesquisa do Estado de São Paulo (FAPESP - Proc. 2009/53006-0 and Proc. 2010/18504 -7) for the financial support.

\section{REFERENCES}

Antoniosi Filho NR, Mendes OL, Lanças FM. 1995. Computer predition of triacylglycerol composition of vegetable oils by HRGC. Chromatographia 40, 557-562.

AOCS. American Oil Chemists' Society. 2004. Official methods and recommended practices of the Am. Oil Chem. Soc.. AOCS Press, Urbana, USA.

Awad TS Marangoni AG. 2006. Ingredient interactions affecting texture and microstructure of confectionery chocolate, enMcPherson A, Gaonkar AG (Eds.) Ingredient Interactions: Effects on Food Quality. CRC Press, Boca Raton, págs. 424-471. 
Beckett ST. 2008. The Science of Chocolate. RSC Publishing, Cambridge, UK.

Bessler TR, Orthoefer FT. 1983. Providing lubricity in food fat systems. J. Am. Oil Chem. Soc. 60, 17651768.

Bockisch M. 1998. Fats and Oils Handbook. AOCS Press, Urbana, USA.

Campos R.2005. Experimental Methodology, en Marangoni AG (Ed.) Fat Crystal Networks. Marcel Dekker, New York, págs. 267-349.

Campos R, Ollivon M, Marangoni AG. 2010. Molecular composition dynamics and structure of cocoa butter. Cryst. Growth Des. 10, 205-217.

Chaiseri S, Dimick PS.1995. Dynamic crystallization of cocoa butter. Characterization of simple lipids in rapid- and slow-nucleating cocoa butters and their seed crystals. J. Am. Oil Chem. Soc. 72, 1491-1496.

Codevasf.2009. Cadeia produtiva de cacau: oportunidade de investimento em cacauicultura no Vale do São Francisco e do Parnaíba. Codevasf,Brasília, BR.

Deman JM. 1983. Consistency of fats: a review.J. Am. Oil Chem. Soc. 60, 82-87.

El-Mallah MH, Megahed MG. 1998. Studies on cocoa butter-replacer mixtures suitable for the local chocolate production. Grasas Aceites 49, 446-449.

Gunstone FD, Harwood JL. 2007. Occurrence and characterization of oils and fats, en: GunstoneFD, Dijkstra AJ (Eds.) The Lipid Handbook. CRC Press, Boca Raton, págs. 37-141.

Haighton AJ. 1959. The measurement of the hardness of margarine and fats with cone penetrometers. J. Am. Oil Chem. Soc. 36, 345-348.

Hartman L, Lago RCA. 1973. Rapid preparation of fatty acid methyl esters from lipids. Lab. Practice 22, 475-476.

Jeyarani T, Reddy Y. 2005. Physicochemical evaluation of vanaspati marketed in India. J. Food Lipids 12, 232-242.

Jie MSFLK, Mustafa J. 1997. High resolution nuclear magnetic resonance spectroscopy - applications to fatty acids and triacylglycerols. Lipids 32, 1019-1034.

Kosugi Y, Oshima A, Koike S, Fukatsu M, Minami K, Miyake Y, Masui K. 2004. Use of rhizopus delemar lipase as compared with other lipases for determination of $s n-2$ fatty acids in triacylglycerol. J. Am. Oil Chem. Soc. 81, 235-239.

Lehrian DW, Keeney PG, Butler DR. 1980. Triglyceride characteristics of cocoa butter from cacao fruits matured in a microclimate of elevated temperature. $J$. Am. Oil Chem. Soc. 57, 66-69.

Lipp M, Anklam E. 1998. Review of cocoa butter and alternative fats for use in chocolate - part A. Compositional data. Food Chem. 62, 73-97.

Lipp M, Simoneau C, Ulberth F, Anklam E,Crews E, Brereton P, Greyt W, Schwack W, Wiedmaier C. 2001. Composition of genuine cocoa butter and cocoa butter equivalents. J. Food Comp. Anal. 14, 399-408.

Loisel C, Keller G, Lecq G, Bourgaux C, Ollivon M. 1998. Phase transitions and polymorphism of cocoa butter. J. American Oil Chem. Soc. 75, 425-439.

Lonchampt P, Hartel RW. 2004. Fat bloom in chocolate and compound coatings. Eur. J. Lipid Sci. Technol. 106,241-274.

Luccas V.2001. Fracionamento térmico e obtenção de gorduras de cupuaçu alternativas à manteiga de cacau para uso na fabricação de chocolate. University of Campinas, Campinas, BR.
Neff WE, Byrdwell WC, List GR. 2001. Triacylglycerol structures of food fats high in saturated acids by HPLC and mass spectrometry. J. Liq. Chromatogr. Relat. Technol. 24, 837-854.

Norberg S. 2006. Chocolate and confectionery fats, en Gunstone FD (Ed.) Modifying Lipids for Use in Food. Woodhead Publishing, Cambridge, págs. 488-516.

Ribeiro APB, Grimaldi R, Gioielli LA, Gonçalves LAG. 2009. Zero trans fats from soybean oil and fully hydrogenated soybean oil: physicochemical properties and food applications. Food Res. Int. 42, 401-410.

Rodrigues JN, Torres RP, Mancini-Filho J, Goielli LA.2007. Physical and chemical properties of milkfat and phytosterol esters blends. Food Res. Int. 40, 748-755.

Segall SD, Artz WE, Raslan DS, Ferraz DP, Takahashi JA.2005. Analysis of triacylglycerol isomers in Malaysian cocoa butter using HPLC - mass spectrometry. Food Res. Int. 38, 167-174.

Silva RC, Soares DF, Lourenço MB, Soares,FASM, Silva KG, Gonçalves MI, Gioielli LA. 2010. Structured lipids obtained by chemical interesterification of olive oil and palm stearin. LWT - Food Sci. Technol. 43, 752758.

Silwood CJL, Grootveld M. 1999. Application of highresolution, two-dimensional $1 \mathrm{H}$ and $13 \mathrm{C}$ nuclear magnetic resonance techniques to the characterization of lipid oxidation products in autoxidized linoleoyl/ linolenoylglycerols. Lipids 34, 741-756.

Shi Y, Liang B, Hartel RW. 2005. Crystal morphology, microstructure, and textural properties of model lipid system. J. Am. Oil Chem. Soc. 82, 399-408.

Shukla VKS. 2006. Cocoa Butter, Cocoa Butter Equivalents, and Cocoa Butter Substitutes, en Akoh CC (Ed.)Handbook of Functional Lipids. CRC Press, Boca Raton, págs. 279-307.

Subramaniam PJ. 2000. Confectionery products, enKilcast D (Ed.) The Stability and Shelf-life of Food. CRC Press, Boca Raton, págs. 221-245.

Takagi T, Ando Y.1995. Stereospecific analysis of monounsaturated triacylglycerols in cocoa butter. J. Am. Oil Chem. Soc. 72, 1203-1206.

Timms RE. 2003. Confectionery Fats Handbook. The Oily Press, Bridgwater, UK.

Tucci MLS, Abreu MF, Coral FJ, Futino, AM, Alfonsi, RR, Saes LA. 1996. Teores de g ordura e ácidos graxos de clones de cacau nas condições do Vale do Ribeira (SP). Bragantia 55, 207-213.

Vlahov G. 1998. Regiospecific analysis of natural mixtures of triglycerides using quantitative ${ }^{13} \mathrm{C}$ nuclear magnetic resonance of acyl chain carbonyl carbons. Magn. Reson. Chem. 36, 359-362.

Vlahov G.2005. ${ }^{13} \mathrm{C}$ nuclear magnetic resonance spectroscopy to check 1,3-random, 2- random pattern of fatty acid distribution in olive oil triacylglycerols. Spectroscopy 19, 109-117.

Wang H, Wu H, Ho C, Weng X. 2006. Cocoa butter equivalent from enzymatic interesterification of tea seed oil and fatty acid methyl esters. Food Chem. 97, 661-665.

Yamada K, Ibuki M, McBrayer T. 2005. Cocoa butter, cocoa butter equivalents, and cocoa butter replacers, en Lai O, Akoh CC (Eds.) Healthful Lipids.CRC Press, Boca Raton, págs. 279-307.

Recibido: $10 / 6 / 11$ Aceptado: 8/9/11 